\title{
Frailty at the front door
}

\author{
Author: Zoe Wyrko ${ }^{\mathrm{A}}$
}

Significant numbers of older people attending hospital can be considered to be frail or living with frailty. This is a multicomponent syndrome with many manifestations that leads to poorer outcomes in terms of mortality, morbidity and institutionalisation. Recognition and management of frailty can be challenging, and requires a true multidisciplinary approach, but appropriate assessment and subsequent intervention have been proven to be beneficial. This article discusses the background to frailty, and a number of validated frailty scores which can be applied by non-specialists in the acute environment. It highlights other resources which are available to help with the management of this complex group of patients, and discusses potential local and national service developments in this area.

Increasing age is not automatically associated with a decline in health. Of much greater relevance to those working in hospitals is the way a person, physiologically and functionally, deals with the consequences of ageing. Those who do not adapt well to the depletion of their homeostatic reserves can be deemed to be 'frail' or 'living with frailty'.

Frailty can be defined as a 'clinically recognizable state of increased vulnerability resulting from aging associated decline in reserve and function across multiple physiologic systems such that the ability to cope with everyday or acute stressors is compromised'. ${ }^{1}$

Rather than a simple, single condition, frailty is now being seen as a syndrome with multiple components, the manifestation of Isaac's 'geriatric giants'. The effects of frailty on older people attending hospital can be easily seen in any medical admissions unit, but are often inadequately recognised. This leads to harmful diagnoses such as off-legs, acopia or $\mathrm{UTI},{ }^{2}$ a collection of terms which identify the likely presence of the frailty syndrome, but without an attempt to find the stressor that has resulted in the decline. Underlying frailty will often, but not always, be the reason that a person becomes unable to walk or more prone to falling at the time of an acute illness; it can be the reason that their mild cognitive impairment, usually allowing the maintenance of an independent lifestyle with only minor support, deteriorates to the extent that they become lost within their own environment.

Author: ${ }^{A}$ consultant geriatrician, Queen Elizabeth Hospital, Birmingham, UK
Adverse effects, such as death, falls, delirium and decreased function, are all more likely to occur post-illness in a person with frailty than without, ${ }^{3-5}$ thus recognition of the syndrome in an attempt to mitigate against its effects is vital. People with frailty are more likely to enter institutional care than matched controls without frailty. ${ }^{6-8}$ It must be remembered that frailty can be a dynamic process, with improvements in function achievable if interventions are correct. Unfortunately though, a spiral of decline once a person becomes frail is the most likely outcome.

Frailty is not an inevitable consequence of ageing. It is estimated that between two-thirds and three-quarters of those aged over 85 years are not frail. ${ }^{6}$ Misuse of the term 'frailty' must not be a way of legitimising age discrimination and healthcare rationing.

\section{Frailty models}

Two recognised models of frailty are directing both scientific and applied research in this field. Considerable efforts are being made to devise simple but validated frailty tools from this work, in order to improve the care delivered to this group of patients.

\section{Key points}

Frailty is not an inevitable consequence of ageing.

Frailty is best thought of as a syndrome with multiple possible components, rather than a single condition.

People with frailty, who experience an acute illness, will have worse outcomes (death, institutionalisation and increased dependence) than those who are not frail with similar comorbidities.

Validated ratings scores to assess the degree of frailty a person has do exist, but they can be cumbersome to use in the acute hospital environment.

Comprehensive geriatric assessment associated with a tailored management plan is the gold standard intervention for diagnosis and treatment of frailty.

KEYWORDS: Frailty, frailty scales, older people, comprehensive geriatric assessment, multi-disciplinary 


\section{Box 1. Fried frailty phenotype indicators. ${ }^{3}$}

$>$ Weight loss: self-reported weight loss of $>4.5 \mathrm{~kg}$ or recorded weight loss of $\geq 5 \%$ per year.

Self-reported exhaustion: self-reported exhaustion on Center for Epidemiologic Studies depression scale (3-4 days per week or most of the time).

> Low energy expenditure: energy expenditure $<383 \mathrm{kcal} /$ week (men) or $<270 \mathrm{kcal} /$ week (women).

Slow gait speed: standardised cut-off times to walk 4.57 m, stratified by sex and height.

> Weak grip strength: grip strength, stratified by sex and body mass index.

\section{The frailty phenotype model}

Fried et al carried out secondary analysis of a dataset of a population aged over 65 years to identify five variables (Box 1). Presence of these factors was used to categorise participants into frail (three or more), pre-frail (one or two) or not frail (none). Outcomes assessed at three and five years were death, hospitalisations, falls, mobility and function. The frail cohort were significantly more likely to have died or have an adverse outcome than the non-frail. ${ }^{3}$

\section{The cumulative deficit model}

As part of continuing work with the Canadian Study of Health and Ageing, ${ }^{9}$ Rockwood et al collected information on 92 deficit variables (including symptoms, signs, laboratory results and disabilities) to define frailty. The greater number of deficits, the more likely frailty is to be present. This model allows frailty to be graded in a more precise way than with the phenotype model, and subsequent work has concentrated on reducing the number of variables in order to maintain validity, but create a simplified tool with greater clinical application. ${ }^{10,11}$

The clinical frailty scale (see http://geriatricresearch. medicine.dal.ca/pdf/Clinical\%20Faily\%20Scale.pdf) is a simplified depiction of this deficit model, however it is validated to categorise frailty in a person after they have undergone a comprehensive geriatric assessment, rather than to define a person as frail. ${ }^{12}$

Long-term outcomes between the two models are comparable. ${ }^{6}$

\section{Diagnosis and treatment of frailty}

A frequently asked question, even among geriatricians is 'how can I best diagnose frailty?', and whether there are simple tools which can be used, particularly in an acute situation, to risk stratify older people in order to inform their future care.

\section{Comprehensive geriatric assessment}

Comprehensive geriatric assessment (CGA) is the backbone of a geriatricians work, and can be defined as a 'multidisciplinary, diagnostic process to describe the medical, psychological and functional capabilities of a frail older person in order to keep a co-ordinated, integrated plan for long-term treatment and follow-up. ${ }^{13}$ It has been shown to be the gold standard for diagnosing frailty, with results strongly associated with the research standard for predictions of death and institutionalisation. ${ }^{6}$ This process can be carried out in hospital or community settings with the team led by a geriatrician or community geriatrician, or a primary care physician specially trained in the care of older people. The multidisciplinary team includes professionals such as specialist nurses, physiotherapists, occupational therapists and social workers. ${ }^{12}$ It has been shown that in hospital, those who receive inpatient CGA on specialist elderly care wards are more likely to return home, are less likely to have cognitive or functional decline, and have lower mortality rates than those who are admitted to general wards. ${ }^{14}$

\section{The Edmonton Frail Scale}

The Edmonton Frail Scale is an easy to perform test which broadly assess function in a number of areas, including functional dependence, mood, nutritional state and general health (Table 1). It is feasible for routine use by geriatricians and non-specialists and is often used in perioperative liaison services for older people. It is valid and reliable, and identifies the presence of frailty well, but does not give the diagnostic advantages that will occur with CGA. ${ }^{15}$

\section{Other simple tests for frailty}

A review found that a number of tests which can be performed in any environment each have high sensitivity for identifying the presence of frailty, but only moderate sensitivity. ${ }^{12}$ These including the following:

$>$ slow walking speed: $>5$ seconds to walk 4 metres

$>$ timed up-and-go test: $>10$ seconds to stand from a chair, walk 3 metres, turn round and sit down again

> a score of 3 or above on the PRISMA 7 questionnaire (Box 2).

\section{The future of frailty}

Frailty is coming to the forefront of health and political agendas. It is frequently said that health and social care systems are not designed to function with the current levels of demand. Perversely, this is actually a measure of success with many more people living into deep old age as a consequence of medical advances, and just some of these developing the

\section{Box 2. PRISMA 7 questions. Reproduced with} permission. ${ }^{12}$

Are you more than 85 years?

$>$ Male?

In general do you have any health problems that require you to limit your activities?

$>$ Do you need someone to help you on a regular basis?

$>$ In general do you have any health problems that require you to stay at home?

$>$ In case of need, can you count on someone close to you?

Do you regularly use a stick, walker or wheelchair to get about? 
Table 1. Edmonton Frail Scale. Reproduced with permission. ${ }^{15}$

\begin{tabular}{|c|c|c|c|c|}
\hline Domain & Item & 0 points & 1 point & 2 points \\
\hline Cognition & $\begin{array}{l}\text { Please imagine that this pre-drawn circle is a clock. I } \\
\text { would like you to place the numbers in the correct } \\
\text { positions then place the hands to indicate a time of } \\
\text { 'ten past eleven' }\end{array}$ & No errors & $\begin{array}{l}\text { Minor spacing } \\
\text { errors }\end{array}$ & Other errors \\
\hline \multirow[t]{2}{*}{ General health status } & $\begin{array}{l}\text { In the past year how many times have you been } \\
\text { admitted to hospital? }\end{array}$ & 0 & $1-2$ & $\geq 2$ \\
\hline & In general, how would you describe your health? & $\begin{array}{l}\text { Excellent, very } \\
\text { good, good }\end{array}$ & Fair & Poor \\
\hline $\begin{array}{l}\text { Functional } \\
\text { independence }\end{array}$ & $\begin{array}{l}\text { With how many of the following activities do you } \\
\text { require help: meal preparation, shopping, } \\
\text { transportation, telephone, housekeeping, laundry, } \\
\text { managing money, taking medications? }\end{array}$ & $0-1$ & $2-4$ & $5-8$ \\
\hline Social support & $\begin{array}{l}\text { When you need help, can you count on someone who } \\
\text { is willing and able to meet your needs? }\end{array}$ & Always & Sometimes & Never \\
\hline \multirow[t]{2}{*}{ Medication use } & $\begin{array}{l}\text { Do you use five or more prescription medications on a } \\
\text { regular basis? }\end{array}$ & No & Yes & \\
\hline & $\begin{array}{l}\text { At times do you forget to take your prescription } \\
\text { medications? }\end{array}$ & No & Yes & \\
\hline Nutrition & $\begin{array}{l}\text { Have you recently lost weight so that your clothing has } \\
\text { become looser? }\end{array}$ & No & Yes & \\
\hline Mood & Do you often feel sad or depressed? & No & Yes & \\
\hline Continence & $\begin{array}{l}\text { Do you have a problem with losing control of urine } \\
\text { when you don't want to? }\end{array}$ & No & Yes & \\
\hline Functional performance & $\begin{array}{l}\text { I would like you to sit in this chair with your back and } \\
\text { arms resting. When I say 'go,' please stand up and } \\
\text { walk to the mark on the floor (approximately } 3 \text { metres } \\
\text { away), turn round return to the chair and sit down }\end{array}$ & $0-10$ seconds & $\begin{array}{l}11-20 \\
\text { seconds }\end{array}$ & $\begin{array}{l}>20 \text { seconds, } \\
\text { patient unwilling or } \\
\text { requires assistance }\end{array}$ \\
\hline Total & Final score is the sum of column totals & & & 117 \\
\hline
\end{tabular}

Scoring: not frail 0-5; apparently vulnerable $6-7$; mild frailty $8-9$; moderate frailty $10-1$; severe frailty $12-7$.

frailty syndrome. It should be remembered that the NHS was founded at a time when $48 \%$ of the population died before the age of $65 . .^{16}$

The Royal College of Physicians (RCP) published an acute care toolkit on the subject of frail older people in $2012 .{ }^{17}$ Subsequently, the Future Hospital Commission report ${ }^{18}$ emphasised the challenges provided by this group of patients, and three of the four projects taking the Future Hospital development work forward are specifically focused on improving care in those living with frailty.

The British Geriatrics Society (BGS), working with the Royal College of General Practitioners and AgeUK have published Fit For Frailty, ${ }^{12}$ advice aimed at all levels of health and social care professionals encountering older people living with frailty in community and outpatient settings. The second part of this work is guidance directed at senior clinicians, managers and commissioners on the development of services for those who may be frail. The 'Silver Book' also contains essential information on how to prevent harm to those with frailty accessing urgent care. ${ }^{19}$

Frailsafe (www.frailsafe.org.uk) is a BGS-led, Health Foundation-supported, collaborative project with other partners, including the RCP and AgeUK. Frailsafe is a checklist initiative with the aim of improving measured quality of care for frail older patients admitted to NHS hospitals with medical emergencies by July 2016. It is currently being trialled in a number of admissions units around the UK, with the aim of national roll out within the next twelve months.

The King's Fund touches on frailty issues in many of its publications, however in their 2014 publication Making our health and care systems fit for an ageing population, ${ }^{16}$ Oliver et al discuss how to improve care for those who are frail at a macro and micro level.

In their recent commission on hospital care for frail older people ${ }^{20}$ the Health Services Journal set out clear advice to policy makers and commissioners on the systems level changes which must be properly established and funded in order to both improve quality and value of care.

AgeUK are prioritising awareness of frailty and in their recent report Understanding the lives of older people living with frailtya qualitative investigation ${ }^{21}$ they discuss preferred terminology and a number of case studies, in order to better inform service developments. 
The Acute Frailty Network (www.acutefrailtynetwork. org.uk/) was launched in January 2015 and is an additional collaboration with the aim of optimising acute care of frail older people in England, by supporting the widespread adoption and improvement of acute frailty services.

\section{How can this knowledge be applied in an acute setting?}

There is considerable overlap between geriatric medicine and internal medicine, with almost all geriatricians fully trained in both areas and providing significant input to acute on-call rotas. However, in some services, many older people who might benefit from CGA will not be able to access this immediately. Where this gap exists, collaborative working among general and acute physicians with geriatricians providing appropriate clinical support and training in essential geriatric medical skills is beneficial; other disciplines such as specialised occupational therapists or nurse practitioners can also provide many elements of CGA.

It should be remembered that there is no 'one-size-fits-all model' for the care of older people, due to appropriate variance in services, both internal and external (for example ward set-up and social services provision). Thought needs to be given to how to correctly identify those who are frail or at risk of becoming frail in the hospital environment, and act early in order to prevent avoidable harm. It is worth remembering that CGA is iterative and continuous, so while it should be started promptly, it can be continued and completed in a different setting such as a specialist ward or even community or outpatient setting. ${ }^{22}$

The three simple screening questions which are part of the Frailsafe tool have been shown to be sensitive in identifying those at risk of frailty, and can be easily answered by any staff member. A single positive answer leads on to further assessment.

$>$ Does the person have reduced mobility (compared to independently mobile)?

$>$ Is the person confused?

$>$ Are they from a care home?

A 'yes' answer to any of these could then lead to further targeted assessments carried out by a variety of staff members of different disciplines, depending on local availability. There could also be a role for use of a scale such as the Edmonton Frailty scale at this point to direct treatment. Potential examples of multidisciplinary involvement include the following.

$>$ Early physiotherapy and occupational therapy input to establish usual functional baseline, provide walking aids and prevent unnecessary deterioration by prolonged bed rest. The Society of Acute medicine recently published guidelines for isolated therapy input on acute units. ${ }^{23}$

$>$ Pharmacy involvement for medicines reconciliation to reduce iatrogenic harm.

$>$ Focused medical review paying attention to the presence of delirium, and interventions to reduce its occurrence, for example the use of equipment such as bedrails, cannulas and urinary catheters.

> Accurate assessments of falls risk and pressure sore risk, and interventions to reduce the opportunities for these to occur.
Assessments and interventions as suggested above could then lead to easier identification of the most appropriate patients to be seen by a geriatrician, as well as improve flow through acute services, with patients placed on appropriate wards, transferred to intermediate care, or returning home in a timely way.

\section{Conclusion}

The increasing recognition of frailty syndrome beyond the traditional boundaries of geriatric medicine is to be welcomed. Heightened awareness, together with financial constraints, give an opportunity to develop cost-effective, high-quality care for this group of people, resulting in better outcomes and an improvement in long-term care planning. Ongoing research programmes, together with developing networks and collaborations, will lead to a portfolio of tools and checklists to aid the non-specialist in recognising and managing patients who are frail.

\section{References}

1 Xue Q-L. The frailty syndrome: definition and natural history. Clin Geriatr Med 2011;27:1-15.

2 Oliver D. The geriatrics 'profanisaurus.' Words and phrases we should ban? London: British Geriatrics Society, 23 December 2013. Available online at https://britishgeriatricssociety.wordpress.com/ tag/profanisaurus/ [Accessed 8 May 2015].

3 Fried LP, Tangen CM, Walston J et al. Frailty in older adults: evidence for a phenotype. J Gerontol A Biol Sci Med Sci 2001;56: M146-56.

4 Song X, Mitnitski A, Rockwood K. Prevalence and 10-year outcomes of frailty in older adults in relation to deficit accumulation. J Am Geriatr Soc 2010;58:681-7.

5 Eeles EM, White SV, O'Mahony SM et al. The impact of frailty and delirium on mortality in older inpatients. Age Ageing 2012; 41:412-6.

6 Clegg A, Young J Iliffe S et al. Frailty in elderly people. Lancet 2013;381:752-62.

7 Gill TM, Gahbauer EA, Allore HG, Han L. Transitions between frailty states among community-living older persons. Arch Intern Med 2006;166:418-23.

8 Rockwood K, Howlett SE, MacKnight C et al. Prevalence, attributes, and outcomes of fitness and frailty in community-dwelling older adults: report from the Canadian study of health and aging. J Gerontol A Biol Sci Med Sci 2004;59:1310-7.

9 Rockwood K, Song X, MacKnight C et al. A global clinical measure of fitness and frailty in elderly people. CMAJ 2005;173:489-95.

10 Mitnitski AB, Mogilner AJ, Rockwood K. Accumulation of deficits as a proxy measure of aging. ScientificWorldJournal 2001;1:323-36.

11 Rockwood K, Mitnitski A. Frailty in relation to the accumulation of deficits. J Gerontol A Biol Sci Med Sci 2007;62:722-7.

12 British Geriatrics Society. Fit for frailty. Consensus best practice guidance for the care of older people living with frailty in community and outpatient settings. London: British Geriatrics Society 2014. Available online at www.bgs.org.uk/campaigns/fff/fff_full.pdf [Accessed 8 May 2015].

13 Stuck AE, Egger M, Hammer A et al. Home visits to prevent nursing home admission and functional decline in elderly people: systematic review and meta- regression analysis. J Amer Med Assoc 2002;287:1022-8.

14 Ellis G, Whitehead MA, O'Neill D et al. Comprehensive geriatric assessment for older adults admitted to hospital. Cochrane Database Syst Rev 2011;(7):CD006211. 
15 Rolfson DB, Majumdar SR, Tsuyuki RT et al. Validity and reliability of the Edmonton Frail Scale. Age Ageing 2006;35:526-9.

16 Oliver D, Foot C, Humphries R. Making our health and care systems fit for an ageing population. London: The King's Fund, 2014.

17 Royal College of Physicians. Acute care toolkit 3: acute medical care for frail older people. London: RCP, 2012.

18 Future Hospital Commission. Future hospital: caring for medical patients. A report from the Future Hospital Commission to the Royal College of Physicians. London: Royal College of Physicians, 2013.

19 Banerjee J, Conroy S. Quality care for older people with urgent and emergency care needs. The silver book. Available online at www.bgs. org.uk/campaigns/silverb/silver_book_complete.pdf [Accessed 8 May 2015].

20 HSK/Serco. Commission on hospital care for frail older people. Main report. November 2014. Available online at www.hsj.co.uk/ Journals/2014/11/18/1/q/r/HSJ141121_FRAILOLDERPEOPLE_ LO-RES.pdf [Accessed 8 May 2015]
21 Ipsos MORI. Understanding the lives of older people living with frailty - a qualitative investigation. London: Age UK, March 2014. Available online at www.ageuk.org.uk/professional-resources-home/research/ social-research/living-with-frailty/ [Accessed 8 May 2015].

22 Welsh TJ, Gordon AL, Gladman JR. Comprehensive geriatric assessment - a guide for the non-specialist. Int J Clin Pract 2014;68:290-3.

23 Mearns N, Duguid I, Physiotherapy and Occupational Therapy Group. Physiotherapy and occupational therapy in the acute medical unit. Edinburgh: Society for Acute Medicine, October 2011 (revised April 2015). Available online at www.acutemedicine.org.uk/wpcontent/uploads/2015/04/PTOT-AMU-Guidance-Document-2015. pdf [Accessed 5 June 2015].

Address for correspondence: Dr Z Wyrko, Queen Elizabeth Hospital Birmingham, Mindelsohn Way, Edgbaston, Birmingham B15 2GW, UK.

Email: zoe.wyrko@uhb.nhs.uk

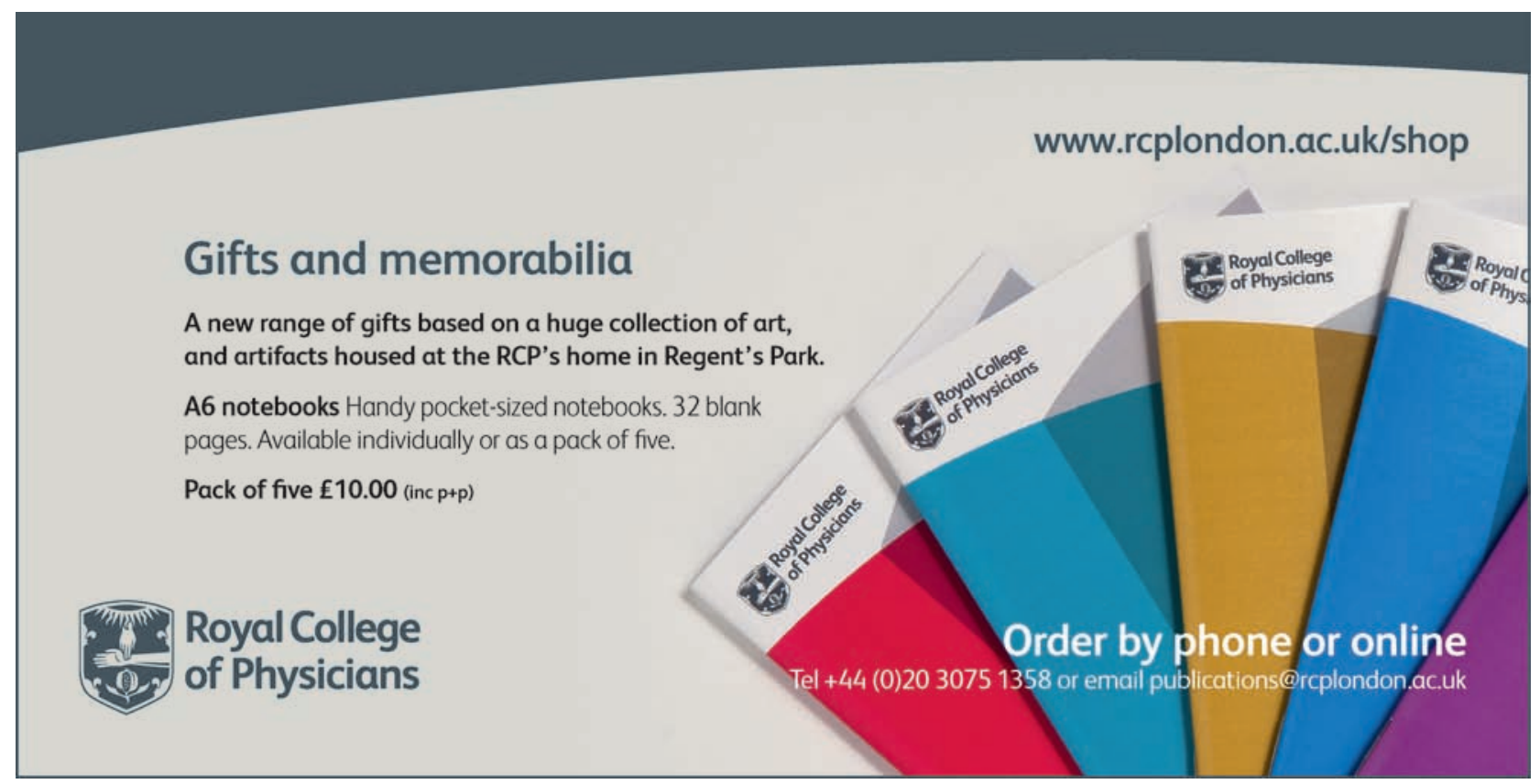

